\title{
Poles Apart or Bedfellows? Re-conceptualising Information Systems Success and Failure
}

\author{
Dennis Hart ${ }^{1}$ \\ School of Accounting and Business Information Systems, \\ The Australian National University \\ email: dennis.hart@anu.edu.au \\ Leoni Warne ${ }^{2}$ \\ Defence Systems Analysis Division, DSTO \\ email: leoni.warne@dsto.defence.gov.au
}

\begin{abstract}
It is commonly stated that information systems continue to be plagued by persistently high rates of failure. However, we argue in this paper that the relationship between success and failure is more complex than usually assumed, and based in the different expectations that different stakeholders have of a development effort. The expectation failure concept of Lyytinen and Hirschheim is used as a starting point for discussion leading to the introduction of a new concept that we call 'defining characteristics'. We then proceed with a discussion of the implications of this new concept for ideas about success and failure and use a case study conducted by the second author to illustrate these ideas.
\end{abstract}

\section{Introduction}

Information systems success and failure have been much discussed in the literature for many years (e.g. Brooks, 1974; Davis et al, 1992; DeLone and McLean, 1992; Fortune and Peters, 2005; Lucas, 1975; Lyytinen and Hirschheim, 1987; McFarlan, 1981; Sauer, 1993). It seems, however, that the general assumption in all of these cases has been that the two concepts, success and failure, are inverses of each other. That is, a failure is by definition not a success and vice versa. While this appears natural enough and in accord with common sense, we argue against this view in this paper contending instead that the

\footnotetext{
1 Previously of the Australian Defence Force Academy when this work was undertaken.

2 Previously of the University of Canberra when this work was undertaken.
} 
criteria that distinguish between success and failure are best regarded as being independent of each other. If this is admitted then it suddenly becomes possible for an information system or indeed any other project to be not only a success or a failure in the usually understood sense, but also both at once, or neither.

Contrary to common practice in much of the information systems literature dealing with this kind of topic, in what follows we take 'success' and 'failure' to be ground terms. We make no direct attempt to define them, for reasons that will become evident below. Moreover, information systems researchers are increasingly recognising the varying needs and expectations of different stakeholders in information systems development efforts (e.g. Seddon, 1997, 1999; Rai et al, 2002; Fortune and Peters, 2005) and, as we shall emphasise below, this has corresponding implications for their potentially disparate views concerning the eventual success or failure of these efforts.

We further argue that what is critical is to identify, for different stakeholders, the specific factors that will distinguish for them between success and failure. This is consistent with Seddon et al (1999) who say that in 'a world of conflicting human interests and vastly different systems, different sharply-focused measures of IS effectiveness are likely to be needed for different purposes'. Effective elicitation of these factors in the early stages of system development would, we contend, significantly assist developers by giving them an even better understanding than more traditional techniques provide, of what they should achieve, and also avoid doing, in their subsequent efforts.

\section{Success and failure as independent dimensions}

The view of success and failure as converses is commonly held. According to this picture, the two terms are antonyms (e.g. Allen, 1938); success is at one end of a spectrum and failure is at the other. They are 'poles apart':

\section{Failure}

Success

\section{Figure 1: The success/failure spectrum.}

However, we argue that a closer look reveals a more complex relationship between the concepts. For example, five different dictionaries, in their definition of the word 'failure', all include a reference to 'unsuccessful' or 'lack of success'. But in none of them does the definition of 'success' contain any mention of 'avoidance of failure' or the like. So, it seems, to be unsuccessful is to fail but avoidance of failure is not the same as success.

But even this does not appear to be adequate if we consider, for example, the concluding remarks of Bertrand Russell in his autobiography (Russell, 1975). In reviewing a long, rich and full life, he says: 
My work is near its end, and the time has come when I can survey it as a whole. How far have I succeeded, and how far have I failed? ... To this extent I have succeeded. ... [but] ... In these [other] respects there was failure.

So, for Russell, his life and work was both a success and also a failure. It was not simply a case of one or the other for him, but both. However, in making such judgements and statements about success and failure it is manifestly important to be clear about the entity to which the judgement is being applied. For Russell, this entity was his work as a whole whereas of course in this paper our interest is in information systems. Other examples are easy to find or imagine. A person might be successful as (say) a parent and, at the same time, be a failure as a politician; a movie might be judged a critical success but also be a box office failure. Or, indeed, the entity concerned may be judged neither a particular success nor a failure on any count.

On this argument, then, with respect to success and failure there are four basic 'poles' for the entity of interest rather than just two. These are:

- $\quad$ Success and not failure (S and $\sim \mathrm{F}$ );

- Failure and not success (F and $\sim \mathrm{S}$ );

- Success and failure (S and F);

- $\quad$ Not success and not failure $(\sim \mathrm{S}$ and $\sim \mathrm{F})$.

Success and failure no longer face each other from the opposite ends of a linear spectrum containing intermediate possibilities, as in Figure 1, but may instead be present or absent independently of each other. A better picture of their relationship would, therefore, be that shown in Figure 2.

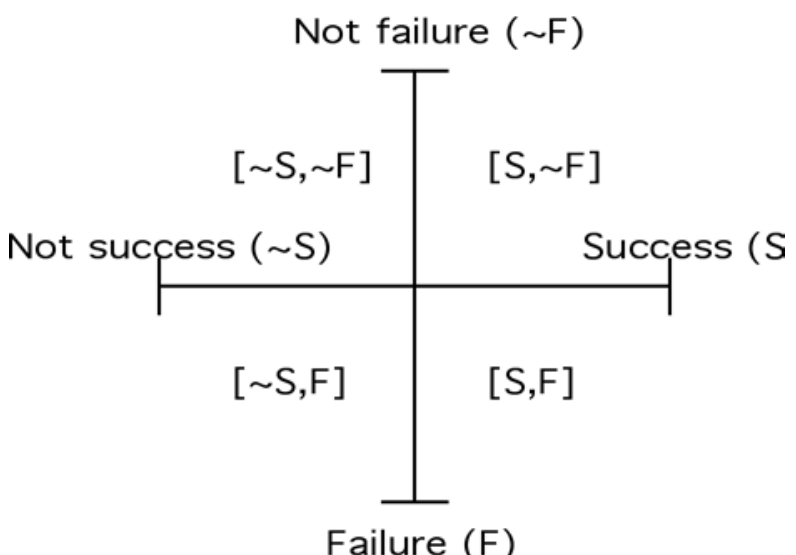

Figure 2: The success/failure matrix. 
The picture of success and failure captured in Figure 2 has been introduced in general terms; our interest in what follows focuses on how this may be applied to information systems and their development.

\section{Success, failure and stakeholder expectations}

If the model of Figure 2 is accepted, the question then arises as to what differentiates 'not success' from 'success' and 'not failure' from 'failure'. Following Lyytinen and Hirschheim (1987), we contend that it is the expectations of the stakeholder concerned that provides this distinction. However, Lyytinen and Hirschheim's concept of expectation failure, which they define as '[an] inability of an IS to meet a specific stakeholder's expectations', does not, in our view, go far enough. We believe it is necessary to further distinguish between different types of expectation, both in their relevance to success or failure, as well as in their relative importance for the stakeholder concerned.

As an example, it is possible that for a certain information system development effort the IS department in an organisation (a stakeholder) expects that the project will be under its overall direction. If this expectation is not fulfilled, which would constitute an expectation failure in Lyytinen and Hirschheim's terms, then the development effort might well be perceived by the IS department as a failure, for them, whatever else happens. On the other hand, if the expectation is fulfilled then the project will not have failed (at least in the eyes of the IS department, and all other things being equal) but is unlikely to be said on this account alone to have succeeded. That is, the expectation of control of the project concerned, by the IS department, would in this case be one of the differentiators between failure and not-failure rather than between success and not-success. Of course there may be other differentiators too, and generally will be. A similar scenario may be painted for success versus not-success. For instance, suppose a particular user group is expecting expanded functionality in an area of their special interest. If the project and resulting information system provides it then they are very likely to regard it as a success, other things being equal. But if not - say only existing basic functionality is maintained - then does that mean it is a failure in their eyes or simply less than a complete success? If the latter, then their expectation of expanded functionality in their special area of interest is, for them, a differentiator between success and not-success and has no direct link to failure or not failure.

\section{Positive and negative expectations}

In most discussions of user requirements it seems to be implicitly assumed that requirements or expectations are of what we would call a 'positive' nature. That is, the system will have some characteristic or provide some feature or functionality. But we contend that expectations may also be negative. For example, a stakeholder may expect that a system will not use a particular 
operating system or should not affect their existing standard operating procedures in certain ways.

Now it could obviously be objected that the distinction being drawn here between positive and negative expectations is artificial and simply dependent on phrasing. From the point of view of a two-valued logic this is of course true. For example, one might argue that saying 'the characteristic of user friendliness must be present' is equivalent to saying that 'the characteristic of user unfriendliness must be absent'. But we are not dealing in simple two-valued logic. Instead it is the psychology and perceptions of stakeholders that are the issue here. The importance of the distinction between positive and negative characteristics lies in the psychological effect in the mind of the respondent. When asked for characteristics that should be present (positive expectations), the effect on the stakeholder is likely to be quite different from that produced when they are asked for characteristics which ought to be absent (negative expectations).

\section{Defining characteristics}

Lyytinen and Hirschheim (1987) as well as Seddon et al (1999) recognise that there are, in general, many stakeholder expectations and many of these may be unstated, vague, unformed or only partially formed, and, initially, even unconscious. This of course represents a practical difficulty for developers who are concerned with satisfying expectations, but even if this were not so, and more fundamentally, Lyytinen and Hirschheim (1987) omit to distinguish between expectations of differing importance and it is, we think, evident that not only may a stakeholder hold many expectations but also that some will carry much greater weight than others. Furthermore, in addition to explicit and well documented expectations, there may also be other implicit or pseudo-rational requirements that remain hidden. Leifer et al (1994) call these 'deep structures'. Hidden expectations could even be the most important from the stakeholder's point of view, and may, in the final analysis, critically affect their attitudes to success and/or failure. The question therefore arises: 'which, among all of the stakeholder expectation(s), are important enough to differentiate between success/not-success and failure/not-failure?'. This is unanswerable in general because expectations are so context and situation dependent. Instead, we use a concept called 'defining characteristics'.

The idea of information system 'defining characteristics' presented here is derived from a philosophical analysis of definition and meaning in language given in Hospers (1967). Discussing definition, Hospers asserts that it is necessary to:

... consider carefully which characteristics of a thing we consider to be defining. A defining characteristic of a thing ... is a characteristic in the 
absence of which the word [under consideration] would not be applicable to the thing. (Emphasis in original).

Furthermore:

... the test of whether a certain characteristic is defining is always this: would the same word still apply if the thing lacked the characteristic? If the answer is no, the characteristic is defining; if the answer is yes, it is merely accompanying.

The simple example of a triangle is used: 'Being three-sided is a defining characteristic of triangles, since nothing would be ... a triangle unless it had three sides ... but being at least two inches in height ... is not a defining characteristic of a triangle ... since something can be a triangle ... and yet be smaller than this.'

This idea can be applied to information systems success and failure in four ways. (paraphrased from Hospers wording above). Firstly:

1. What characteristics would, if absent, prevent the system being classified as a success? Or, equivalently: What characteristics would, if present, make the system a success?

These are the positive expectations on the $\sim$ S...S dimension. There is nothing new here since these expectations may be equated to the traditional mandatory requirements. Now, secondly:

2. What characteristics would, if absent, prevent the system being classified as not a success? Or, equivalently: What characteristics would, if present, make the system not a success?

These are the negative expectations on the $\sim$ S...S dimension. In essence, this question is asking what must be avoided if the system is to be a success. Such a question seems, at least in our experience, to be not usually asked and may well cause the stakeholder responding to think in very different terms about the system under consideration and what it means to him or her. This difference of effect, of the question asked, on the respondent's thinking may be extremely important in eliciting a more complete picture of relevant stakeholder's views. Now, thirdly:

3. What characteristics would, if absent, prevent the system being classified as a failure? Or, equivalently: What characteristics would, if present, make the system a failure?

These are the negative expectations on the $\sim$ F...F dimension and are the things that must be avoided if a failure is to be averted; they are the absolute 'must not do's'. And lastly: 
4. What characteristics would, if absent, prevent the system being classified as not a failure? Or, equivalently: What characteristics would, if present, make the system not a failure?

These are the positive expectations on the $\sim$ F...F dimension. The characteristics being identified here are similar to what are often called 'hygiene' factors in the theory of motivation (Herzberg et al, 1959). They must be present to avoid failure, but their presence is not of itself a guarantee of success.

This leads us now to a definition of 'defining characteristics' in an information systems success and failure context:

A 'defining characteristic' of an information system is any characteristic that is held by a stakeholder to be of such importance that its presence (or absence) will differentiate between success and not success, or failure and not failure.

Presumably, for each individual stakeholder, the number of defining characteristics will be relatively few. However, no assumption is made about the clarity, awareness, breadth, or apparent triviality or otherwise of these characteristics in the perception of the stakeholder holding them. Like the dimensions of success identified by Seddon et al (1999), our concept of defining characteristics is firmly based in the expectations of the stakeholders, unlike any so-called general or objective list of specific system features or characteristics for defining success. Moreover, unlike the expectation failure idea of Lyytinen and Hirschheim (1987), our concept also takes account of the differences in importance of expectations, focusing specifically upon those both positive and negative that will determine overall system success/not-success or failure/not-failure, in the eyes of the stakeholders concerned.

Finally, it is necessary to note that we have presented our analysis of defining characteristics in terms of a priori stakeholder perceptions regarding success and failure and consequently painted a rather static picture of them. There is always the possibility, however, that stakeholder perceptions and therefore potentially also their defining characteristics for a system may change over time, perhaps because of the emergence of unanticipated benefits or disadvantages that were not evident initially. Analysis of stakeholder defining characteristics may therefore need to be a continuing or repeated process rather than a once-off exercise in a system development effort.

\section{Multiple stakeholders}

So far we have considered only a single stakeholder. But, of course, there are in general many stakeholders in an information system development effort. What effect does this have? Our answer is that we must construct a $2 \times 2$ success/failure matrix such as that shown in Figure 2, with its defining characteristics 
differentiating success/not-success and failure/not-failure, for each stakeholder. In effect each stakeholder has a different definition of the information system (Mathieson, 1993). Our diagram now becomes as shown in Figure 3.

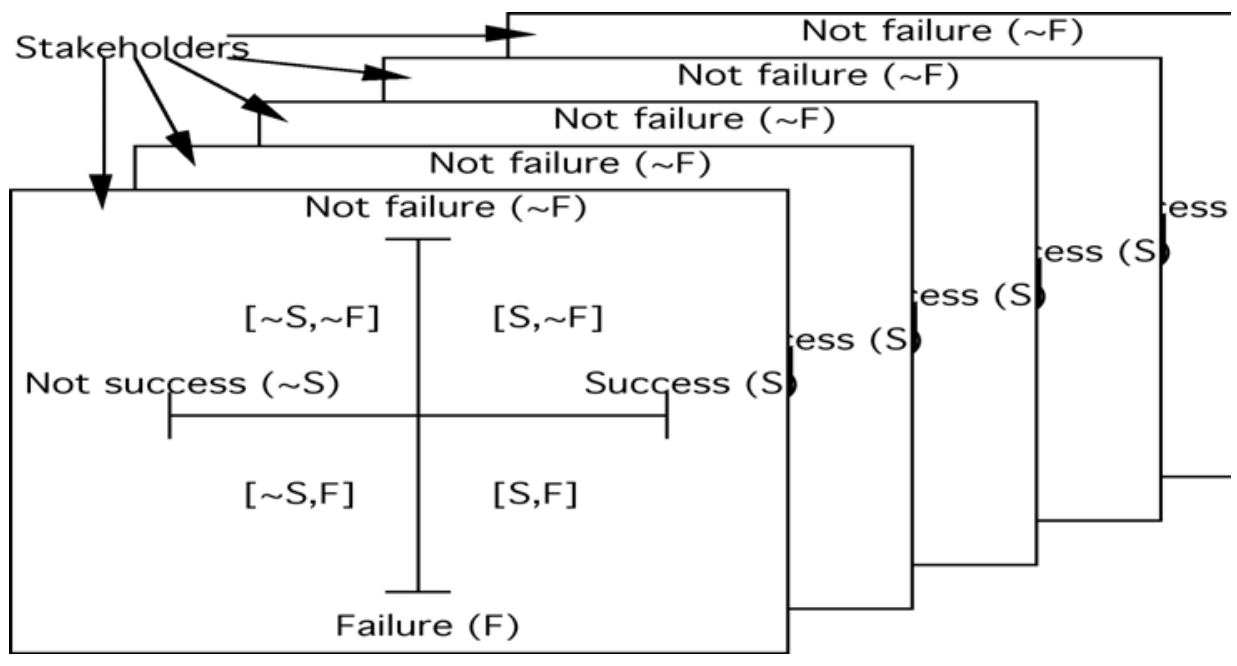

\section{Figure 3: Multiple stakeholders.}

Given a situation like that of Figure 3, what now of the prospects for success overall; that is, for 'success' and 'not failure' for all of the stakeholders? Clearly, this depends on the defining characteristics for each one and we may conclude that for overall success to even be possible requires that none of the set of defining characteristics, across ALL of the stakeholders, be mutually exclusive of any other. In a development effort with many stakeholders this is arguably unlikely and then the probability of success overall, by our definition at least, becomes correspondingly remote. Perhaps this represents a partial explanation of the notoriously high failure rates that characterise large information systems projects.

Seen in this light, it is clearly necessary for information systems developers to uncover and determine, at the outset, both the positive and negative defining characteristics for success/not success and failure/not failure, and to do this for all of the stakeholders of a proposed system. They must be prepared to ask questions like all of 1 to 4 above. However, in practice it would seem from our experience at least that only questions like 1 and 4 are asked in the requirements gathering process, and it may be that it is often the absence of questions like 2 and 3 that contributes to difficulties of understanding and resulting system implementation problems.

It is also possible that defining characteristics could apply not only to a delivered system but also to the development process or the project itself. For example, a particular stakeholder's defining characteristic for failure/not failure might be that a project should be constituted in a certain form, or a development process 
carried out in a certain way, and if it is not then whatever system is finally delivered (if any) may be deemed by them to be a failure regardless.

\section{A case study}

The authors were some years ago involved with a prematurely terminated information system project of substantial size, conducted in a large public sector organisation. Warne (1999) conducted a formal case study of the project. The project was originally intended to run for 9 years and deliver a final system costing some $\$ 250 \mathrm{M}$, but only existed for 2.5 years and expended some $\$ 2.5 \mathrm{M}$ (not including the salaries of the developers). No working software was delivered by the project before its termination, although it did carry out considerable preliminary analysis work and produced large quantities of documentation. Further details regarding the project and case study results can be found in Warne $(1999,2002)$ and Warne and Hart (1996). A discussion and explanatory model concerning the reasons for its termination are also presented in Hart (1997).

In very broad terms (a finer breakdown is possible, but not necessary for our purpose here) the major stakeholders for this project may be identified as:

- $\quad$ End users

- Developers

- Middle/upper management (several subgroups)

- Corporate senior management.

Based on a document study, in-depth interviews with a number of participants in the project and quantitative and qualitative responses to a questionnaire, some of the defining characteristics of the project for these stakeholders can be postulated. It is not, however, possible from our data to identify with any certainty which of these defining characteristics relate to success/not-success or failure/not-failure. Nevertheless, the identified defining characteristics are:

\section{End users}

E1. Improved computer-based support at the operational level for personnel and pay related tasks.

\section{Developers}

D1. Development of an integrated system across the organisation as a whole.

D2. Freedom to proceed to project completion and delivery of a working system.

\section{Middle/upper management (some groups)}

Ml. Improved computer-based support for managerial personnel and pay related tasks.

M2. No effect on existing organisational arrangements or power relationships. 


\section{Corporate senior management}

$\mathrm{Cl}$. Better organisational efficiency in the personnel and pay management areas

C2. Value for money (favourable cost/benefit ratio).

Of these, most are positive defining characteristics. That is, they are characteristics that the project development process, or final system, should have. However, one (M2) is a negative defining characteristic. Note also that characteristics D1 and M2 were mutually exclusive in the context of the organisation concerned and therefore, according to our argument above, the project and the information system it was trying to develop could not succeed overall.

As defining characteristics are married to stakeholders' thoughts and perceptions, a selection of representative comments from project participants is included here to illustrate how the defining characteristics were derived from the case study data. Note also that the comments from one group are often revealing of the defining characteristics of another.

\section{Comments from end users}

'[The Case Study Project] could save [the Organisation] a lot of money, given that it could replace the individual [divisional] systems. For example, one leave system instead of three, one personal particulars system instead of three etc. etc. etc.' (E1)

'A project with great potential; the failure/termination of the project has left a "black hole" in critical management areas (career management, training, personnel data base, strength management, etc.) in terms of MIS.' (E1)

'[The Case Study Project] was a top-down approach at re-engineering a complex and politically sensitive system, fear of a [Central Division] take over and bad PR ensured the project would suffer a death from paralysis by analysis, a good idea, poorly nurtured.' (E1, M2)

'JAD [Joint Application Development] workshops were valuable from both users and developers' perspective. The commonality between [divisions] in personnel admin was (not unexpectedly) very high. The project was defeated by internal and high level politics and by not recognising and extolling the intangible benefits. If the business case was solely dollars/manpower savings driven for recognising benefits in the short term then it had to fail.' (E1, M2)

'Elements were leery of the validity of their data and unwilling to have it controlled and manipulated by outsiders. Differences of approach and tribal processes complicated the manpower management tasks.' (M2)

'The failure of [the Case Study Project] was due principally to vested interests by some elements within the Department who perceived a loss of influence if 
[the Case Study Project] were to have proceeded. This was to the detriment of some of the main intended beneficiaries' (M2)

\section{Comments from developers}

'A harmonious and focused development team in contrast with the short-sighted and divided interests of the traditional [Departmental] power structures. It failed for its political failings - not for technical reasons (or the complexity of the project) ... [the Department] has become less of an organisation in itself; the [different] programs have not developed a "corporate" philosophy, and seem to have difficulty agreeing on anything that has the potential to diminish their own power and control, even where there appears to be a clear business case.' (D1, E1, M2)

'Senior management essentially took no notice from the development team on realistic timing estimates of proposed tasks. The management staff made their own estimates on task timings (to best suit their agenda) and if the developers' estimates did not correspond, the developers' estimates were deemed inaccurate and unacceptable. As a result, task completion dates were continually extended. As it turned out, the original development team task timing estimates were accurate.' (D2)

'[The Case Study Project] threatened several user areas particularly the [Program 1] pay empire. Support was given for [the Case Study Project] by higher levels of user committee in its earlier stages but was later withdrawn at a critical stage in the project and hence [there was] no business case. Many user [groups] were reluctant to offer up savings as they perceived that this would infer that they had "excess" manpower ... Upper [departmental] management does not often have any idea of the real day-to-day IS problems (i.e. [in]accurate data, unfriendly systems etc.). [The Case Study Project] was trying to provide a more efficient, user friendly, integrated system for the [Department].' (D1, M2, E1)

'It could have worked, it should have worked, but it was beaten by vested interests amongst senior [Departmental] officers and their advisers who could not accept compromise, continually looked for their perfect solution and make the job of the developers impossible.' (D1, M2)

'It was a shame that [Departmental] politics and the hidden agendas of some Senior [Departmental] managers played such a large part in the demise of [the Case Study Project]. No doubt, it will be quite some time before the intended users will get the IT support they deserve, and it is highly unlikely that a project like [the Case Study Project] will ever be initiated again. However, if it did, and I had the opportunity to do it all again, I certainly would.' (E1, M2)

'Reasons for failure: vested interests; fear of loss of power; disagreement on savings which would have supported the business case; lack of support from senior user management (not senior [Departmental] management).' (M2) 


\section{Comments from middle/upper management (some groups)}

'Implementation of [the Case Study Project] would have seen the control of a mission critical personnel management tool i.e. the personnel computing system, move from [Divisional] control to [Central Control]. This would have split the [Senior User Managers] from the management tools and threatened the achievement of their missions. If [the Case Study Project] were implemented, the whole personnel management structure of the [Department] would have had to change. In theory the structural change and the personnel computing change should have occurred simultaneously. Obviously the time was not fortuitous for a structural change, therefore the computing initiative was bound to fail.' (M1, M2)

'In my opinion, the major problem was the unwillingness of [the Departmental] management at the most senior level to embrace the need for IS functions and management to be devolved, involving some loss of functional control, but not of policy authority.' [respondent's emphases] (M2)

'There was a naive assumption that because [the Case Study Project] was being reasonably well project-managed that it would succeed. The era of highly centralised domineering IT systems is dead. Hopefully, [extant centralised Departmental project] is the last of its kind.' (M2)

'The whole project seemed to be set up to support [corporate headquarters] rather than the individual [divisional managers]. This led, from an early stage, to confrontation and hostility between developers and some of the user groups.' (C1, M2)

\section{Comments from corporate senior management}

'The Project was visionary and ambitious in that it was to be a catalyst to solve [Departmental] personnel information management deficiencies ... It was terminated because senior management were not committed to it nor to find/agree the savings, without that support [the Case Study Project] had no future and required termination.' (C1, $\mathrm{C} 2)$

'... reasons quite external to [the Case Study Project] and the whole [Case Study Project] debate also played a role. For example, the budgetary situation the Department faced. Even good prospects do not always get funded, and for time sensitive projects like IT, delay can be terminal.' (C2)

'A further problem was the unevenness of benefits across the [divisions] ... I also believe there was a lack of vision and this was driven by resource managers.' (C2, M2)

'The resource bill, both in terms of money and manpower, was much higher than any of the [divisions] could realistically afford at a time of substantial reductions in both areas ... project sponsors did not convince [Departmental] 
manpower planners and resource managers that the proposed system would produce any tangible benefit/utility for them.' (C2)

'[The Case Study Project] was always too large in scope and scale to ever be successful. The hardware and software costs would have been very high and the time-scale of the project would have meant we would get old technology and the old processes by the time it came into service.' $(\mathrm{C} 1, \mathrm{C} 2)$

'[The Case Study Project] had a lot going for it: a goal, high level support, a capable and dynamic project director a large project team, and a disciplined approach. Yet it failed. The reasons are complex, and many players had different reasons for either withdrawing their support or for seeking its demise. My own reasons for arguing against proceeding were very clear - the proposed approach was unlikely to be cost effective, and was high risk. There were other approaches more likely to be cost effective (but still not foolproof) and which were much lower risk. They also offered a much reduced service compared to [the Case Study Project], but not so reduced when compared to then existing and planned systems.' (C1, C2)

'I believe the costs were greater than the savings - it was a simple business assessment.' (C2)

\section{Discussion}

The final assessment of the project is a complex one based on the important expectations or, in our terms, the defining characteristics held by each stakeholder. The actions taken by each stakeholder regarding the project are easily understandable in the context of their defining characteristics. Of greatest interest is the case of the middle management. Their initial approach to the project was supportive based on their expectation of improved systems for personnel and pay management without significant impact on organisational power relationships. Once it became clear that implementation of the system as planned by the project would have involved such impact, they then worked to destroy it and pursued other options for system improvement. On the other hand, stakeholders without this defining characteristic (e.g. the developers) worked hard for the project to continue because this constituted the path to success from the perspective of their own defining characteristics.

Lastly, if the project management had realised what the defining characteristics were for each stakeholder, then care could have been taken to try to satisfy these. Or, if this proved impossible because of mutual incompatibility between them (as was the case), then perhaps the aims or nature of the project itself could have been modified to take this into account. For example, abandonment of at least some of the project's original aims might have permitted it to progress (Sauer, 1993). Or division of it into several separately controlled but related sub-projects could have avoided the problems that were actually encountered 
since it is well known that introducing an information system, especially a centralising one, can have unforeseen social and political impacts (Seddon et al, 1999). The importance of considering the stakeholder defining characteristics is, we think, evident.

\section{Conclusion}

Information systems and their development are complex organisational and social phenomena that are still not well enough understood. There is little doubt that this lack of understanding is a major contributor to the persistently high level of problems and failures that continue to plague information systems development projects. We have argued in this paper that the expectation failure concept of Lyytinen and Hirschheim (1987) is a useful starting point for progress in the analysis of failure, but the lack of differentiation between expectations of different importance is a weakness. The expectation failure concept, combined with recognition of the independence of the concepts of success and failure and also the fact that expectations may be negative as well as positive, is addressed in the discussion and definition of what we have called 'defining characteristics' for information systems.

The case study discussion not only illustrates the concept of defining characteristics but also shows, as is well known from previous studies (e.g. Saarinen, 1996; DeLone and McLean, 2002), that labelling an information system or project as a failure or success is not a simple matter. Indeed, we would argue that such labelling can be misleading and shallow. Our main point, however, is that for different stakeholders who view a project or information system through the different lenses of their own distinct defining characteristics, it may be both a success and a failure at one and the same time. The significance of our argument is that consideration during the requirements analysis process of stakeholder defining characteristics regarding both success/not-success and failure/not-failure, and particularly the negative defining characteristics that we believe are not usually addressed, has the potential to provide additional clues for developers regarding how they may need to modify either the approach taken by an information systems project, or perhaps the aims and constitution of the project itself, in order to increase the prospects for overall success.

\section{References}

Allen, F. S. 1938, Allen's Synonyms and Antonyms, Harper.

Brooks, F. 1974, The Mythical Man Month, Addison-Wesley.

Davis, G. B., Lee, A. S., Nickles, K. R., Chatterjee, S., Hartung, R. and Wu, Y. 1992, 'Diagnosis of an information system failure: A framework and interpretive process', Information and Management, vol. 23, pp. 293-318. 
DeLone, W. H. and McLean, E. R. 1992, 'Information systems success: The quest for the dependent variable', Information Systems Research, vol. 3, no. 1 , pp. 60-95.

DeLone, W. H. and McLean, E. R. 2002, 'Information systems success revisited', Proceedings of the 35th Hawaii International Conference on System Sciences.

Fitzgerald, J. and Fitzgerald A. 1987, Fundamentals of Systems Analysis, 3rd ed., John Wiley and Sons.

Fortune, J. and Peters, G. 2005, Information Systems: Achieving Success by Avoiding Failure, Wiley, Chichester.

Hart, D. 1997, 'Modelling the political aspects of information systems using "Information Wards", Failures and Lessons Learned in Information Technology Management, vol. 1, no. 1, pp. 49-56.

Herzberg, F., Mausner, B. and Synderman, B. 1959, The Motivation to Work, John Wiley and Sons.

Hospers, J. 1967, An Introduction to Philosophical Analysis, Revised ed., RKP.

Leifer, R., Lee, S. and Durgee, J. 1994, 'Deep structures: Real information requirements determination', Information and Management, vol. 27, pp. 27585 .

Lucas, H. C. 1975, Why Information Systems Fail, Columbia University Press.

Lyytinen, K. and Hirschheim, R. 1987, 'Information systems failures - A survey and classification of the empirical literature', Oxford Surveys in Information Technology, vol. 4, pp. 257-309.

Mathieson, K. 1993, 'Variations in user's definitions of an information system', Information and Management, vol. 24, pp. 227-34.

McFarlan, W. 1981, Portfolio approach to information systems', Harvard Business Review, vol. 59, no. 5, pp. 142-50.

Rai, A., Lang, S. S. and Welker, R. B. 2002, 'Assessing the validity of IS success models: An empirical test and theoretical analysis', Information Systems Research, vol. 13, no. 1, pp. 50-69.

Russell, B. 1975, Autobiography, Unwin.

Saarinen, T. 1996, 'An expanded instrument for evaluating information system success', Information and Management, vol. 31, no. 2, pp. 103-18.

Sauer C. 1993, Why Information Systems Fail: A Case Study Approach, Alfred Waller.

Sauer C. 1993, 'Partial abandonment as a strategy for avoiding failure', in Avison D., Kendall J. E. and DeGross J. I. (eds), Human, Organisational, and 
Social Dimensions of Information Systems Development, IFIP Transactions A-24, pp. 143-67.

Seddon, P. B. 1997, 'A respecification and extension of the DeLone and McLean model of IS success', Information Systems Research, vol. 8, no. 3, pp. 240-54.

Seddon, P. B., Staples, S., Patnayakuni, R. and Bowtell, M. 1999, 'Dimensions of information systems success', Communications of the Association of Information Systems, vol. 2, no. 20, November <http://cais.isworld.org/>, Accessed 14 August 2007.

Warne, L. 1999, 'Understanding organisational learning in military headquarters: Findings from a pilot study', Proceedings of the 10th Australasian Conference on Information Systems (ACIS), pp. 1144-58.

Warne, L. 2002, 'Conflict and politics and information systems failure: A challenge for information systems professionals and researchers', in Clarke, S. (ed.), Socio-Technical and Human Cognition Elements of Information Systems, Hershey, PA, Idea Group.

Warne L. and Hart D. 1996, 'The impact of organisational politics on information systems project failure - A case study', Proceedings of the 29th Annual Hawai'i International Conference on Systems Sciences IV, pp. 191-201. 